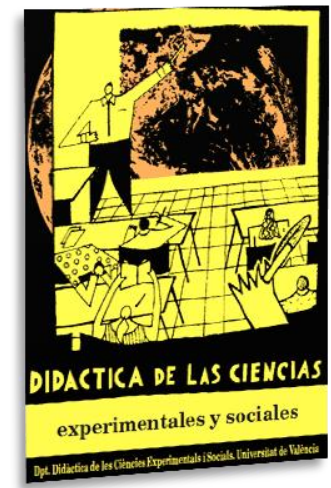

\title{
Juegos de identidad. Las fiestas de moros y cristianos como difusoras de una narrativa histórica nacional
}

\author{
Identity plays. Festivals of Moors and \\ Christians as diffusers of a national \\ historical narrative
}

DOI: $10.7203 / D C E S .35 .13679$

\author{
Patricia Hertel \\ Universidad de Basilea (Suiza) \\ patricia.hertel@unibas.ch
}

\begin{abstract}
RESUMEN: Las fiestas de moros y cristianos están presentes en muchas regiones españolas y representan uno de los momentos más significativos para los pueblos y las ciudades durante el año. Centrado en las fiestas de Alcoi (Alicante), el artículo analiza su historia desde el siglo XIX como un ejemplo de "tradición inventada", siguiendo el concepto del historiador Eric Hobsbawm. Más allá de su carácter carnavalesco, las fiestas han tenido una función educativa a la hora de divulgar narrativas históricas y han intentado crear un sentido de identidad local y nacional para un público amplio, incluido el escolar.
\end{abstract}

Palabras Clave: Usos públicos de la Historia, narrativas nacionales, identidad, tradición, Comunitat Valenciana.

ABSTRACT: The festivals of Moors and Christians exist in many Spanish regions and constitute one of the most important moments for these villages and cities during the year. Taking the example of the festivals in Alcoi (Alicante), this article analyses its history since the nineteenth century as a case study for "invention of tradition", following the concept of the historian Eric Hobsbawm. Beyond its carnivalesque character, the festivals have exerted an educative function in popularizing historical narratives and have tried to create a sense of local and national identities for a broad public, including the school.

KEYWORDS: Public Uses of History, national narratives, identity, tradition, Comunitat Valenciana.

Fecha de recepción: agosto de 2018 Fecha de aceptación: diciembre de 2018

Este artículo parte de la revisión y actualización del trabajo Hertel, P. (2011). Moros y cristianos. Inszenierungen des "Wir" und des "Anderen" als erfundene Tradition im Spanien des 19. Jahrhunderts. En D. Luginbühl et al., Religiöse Grenzziehungen im öffentlichen Raum. Mechanismen und Strategien von Inklusion und Exklusion im 19. und 20. Jahrhundert (pp. 213-229). Stuttgart: Kohlhammer. La autora agradece a Josep Monter Pérez la traducción del alemán al español. 


\section{INTRODUCCIÓN}

Cada año en España centenares de pueblos y ciudades se transforman en un campo de batalla. En Andalucía, en la Comunitat Valenciana, pero también en otras partes del país tienen lugar las fiestas de moros y cristianos. La población local se viste para la ocasión y lucha en un escenario ritual por una propiedad - un castillo o una imagen santa-, que simboliza la identidad del lugar. Cada ciudad tiene sus particularidades en la configuración y desenlace y la realiza en diferentes fechas. El final es siempre el mismo: los moros se rinden, los cristianos ganan.

Las diferentes comparsas acentúan el secular arraigo histórico de esta tradición. Ante la creciente inmigración de musulmanes y la búsqueda de buenas maneras de vivir juntos en una sociedad multicultural, se ha discutido en el espacio público acerca de si estas fiestas son políticamente correctas y oportunas. En la sociedad en su conjunto, y entre los musulmanes españoles, divergen las opiniones sobre si representan un ultraje al islam o si se pueden considerar un inofensivo folclore desligado de formas religiosas (Guia, 2014). Ante tales discusiones, en los últimos años muchas ciudades han adecuado algunos elementos que pueden herir los sentimientos religiosos, especialmente los rituales celebrados en algunos pueblos alrededor del enorme muñeco llamado "La Mahoma" (Guia, 2014; Krom, 2008). La historia sirve como argumento de diversas maneras: como prueba de una tradición mucho más antigua que los actuales debates sobre el islam o como reproche de que las fiestas representarían imágenes históricas ya obsoletas.

Las fiestas han sido analizadas por varias disciplinas como la antropología, la etnografía, las ciencias de la comunicación, la historia y, por supuesto, las ciencias de la educación, dada su evidente conexión con cuestiones relacionadas con la identidad y la alteridad, la relación entre fiestas y vida cotidiana, interferencias o no entre lo religioso, lo secular y lo folclórico, e historia y memoria (Guia, 2014; Brisset Martín, 1998; Baumann, 1991; Harris, 1994; Albert-Llorca y González Alcantud, 2003; Flesler y Pérez Melgosa, 2003; Krom, 2008; Kottmann, 2009; Parra y Segarra, 2012; Domene Verdú, 2015; Ponce Herrero, 2017). La mayoría de los estudios se centra en las últimas décadas del siglo XX y en la actualidad y en las maneras y mecanismos como el "otro" es imaginado y construido en el espacio abierto de las fiestas.

Este artículo propone un enfoque histórico sobre el tema y se centra, especialmente, en el siglo XIX como importante fase de formación de dicha celebración, concebida como una tradición inventada, en el sentido del historiador Eric Hobsbawm: en parte como re-descubrimiento y en parte como creación nueva o nueva combinación de antiguos elementos. Hobsbawm definía este concepto como "a set of practices, normally governed by overtly or tacitly accepted rules and of a ritual or symbolic nature which seek to inculcate certain values and norms of behavior by repetition, which automatically implies continuity with the past" (Hobsbawm 2006 [1983], 1). Toda una serie de transformaciones sociales y políticas favorecieron la aparición de dichas tradiciones, que respondían a nuevas situaciones en la medida en que se proponía la relación con un pasado o creaban uno propio mediante una repetición constante. En el siglo XIX algunas de estas transformaciones derivaron de la industrialización, así como de la diversificación de la sociedad y de la irrupción de nuevas estructuras del trabajo. Además, la nación, como nuevo modelo de organización política, fue legitimada (y mitificada) en relatos históricos evocando determinadas imágenes históricas. En celebraciones jubilares, inauguraciones de monumentos o creaciones de museos el descubrimiento de tradiciones adquirió también una dimensión performativa: cobraban sentido precisamente mediante su puesta en práctica. Con la repetición de estas actuaciones se instauraban rituales sociales que acaban convirtiéndose en tradición e incorporándose, en parte, a la memoria colectiva.

Ante este trasfondo cabe preguntarse por las condiciones y razones de la diversificación de las fiestas, de la invención de su forma y la institucionalización de la praxis festiva. ¿Por qué las batallas rituales entre moros y cristianos se convirtieron en un componente fijo en el calendario de fiestas de una ciudad, de un pueblo? ¿Qué imágenes históricas, qué estilización cultural y religiosa 
del contrincante moro se puede deducir de ellas? ¿Qué idea de comunidad se podía fortalecer con ayuda de las fiestas y por qué?

En la primera parte de este trabajo se ofrece una idea general del mito político de la llamada reconquista y su exposición por parte de la historiografía española decimonónica. Este mito era la narración histórica central de la época y constituía el pretexto material de estas fiestas. En la segunda, se analizan las adaptaciones locales de este mito en la praxis festiva del siglo XIX. Aquí, en la medida en que esto se puede reconstruir a partir de las fuentes, se entra en la dimensión performativa de las fiestas. La tercera parte concluye con una visión sobre las transformaciones de las fiestas en el siglo XX y con su impacto en la sociedad valenciana actual, especialmente en el ámbito educativo.

Hasta el siglo XIX resulta difícil encontrar fuentes rotundas, pues son raras las descripciones detalladas de la praxis de la representación. A menudo ésta sólo se puede reconstruir a grandes trazos. El mérito de los estudios locales es haber aprovechado los archivos y periódicos locales y regionales, que proporcionan hechos y materiales muy valiosos, aunque sin olvidar la intención de los autores de respaldar y cimentar la tradición y el significado de las propias fiestas (Flesler y Pérez Melgosa, 2003, 157-161). El análisis se concentra sobre todo en el territorio de la actual Comunitat Valenciana, especialmente en la fiesta de la ciudad de Alcoi, que adquirió un papel de modelo para otras muchas ciudades del entorno: la praxis de la fiesta se adoptó e imitó de diversas maneras.

\section{EL MITO DE LA RECONQUISTA EN LA HISTORIOGRAFÍA DEL SIGLO XIX}

La guerra medieval contra el islam era un tema central de la historiografía hispánica. Ésta se narró ampliamente en muchos y diferentes escritos en la Edad Media y en la época moderna, empezando por el autor anónimo de la Crónica Mozárabe del año 754, testigo ocular de la primera invasión de tropas musulmanas en el siglo VIII, hasta el jesuita Juan de Mariana (1536-1624), que propagó la unidad religiosa de España siguiendo el espíritu de la Contrarreforma en su Historia General de España.

Sin embargo, los conceptos con que se describió la guerra contra el islam cambiaron en el curso de los siglos. El concepto de restauración, predominante a principios de la época moderna, se vinculaba con la restitución de la libertad en un sentido amplio: restauración de la fe cristiana, del honor y de las antiguas estructuras sociales. La reconquista acentuaba más un componente militar para la conquista y el rechazo de un extranjero territorial (Ríos Saloma, 2006). En conexión con la guerra medieval contra el islam, el concepto de reconquista -utilizado por primera vez de manera predominante en el Compendio cronológico de la Historia de España de José Ortiz y Sanz desde 1795- se impuso progresivamente en el siglo XIX como un concepto exitoso (Ríos Saloma, 2006, 412-427). Esto pone de manifiesto el hecho de que el término reconquista no sólo se refería al proceso de enfrentamientos entre soberanos musulmanes y cristianos o a la conquista concreta de una ciudad o castillo, sino que, cada vez más, se asociaba a una época de lucha contra la dominación islámica en la península (Ríos Saloma 2005, 405). Así, el concepto de reconquista fue convirtiéndose en el mito político nacional de más éxito. Como todos los mitos políticos, proporcionaba una narración que daba sentido al pasado, lo legitimaba y a la vez hacía un llamamiento a una determinada actuación en el presente. La guerra contra el dominio islámico, en la que se mezclaban de manera aparentemente inextricable objetivos religiosos y políticos, aparecía como característica decisiva de toda una época (Bronisch, 1998, 3-7).

Para los historiadores del siglo XIX, que buscaban en el pasado respuestas a las preguntas del presente, la imagen de una reconquista tenía una gran ventaja: difuminaba la heterogeneidad religiosa y política de la Edad Media y proporcionaba una gran narrativa simplificadora, que proclamaba la equiparación de España con el catolicismo, en versiones liberales con determinados valores civilizatorios, reuniendo innumerables relatos mitificadores: el caballero cristiano Rodrigo 
de Vivar aparecía especialmente en interpretaciones católicas como prototipo de un héroe que luchaba por Dios y por la patria. El hecho de que El Cid se hiciera famoso precisamente por su sobrenombre de procedencia árabe sidi (en árabe: señor), que ponía de manifiesto haber servido durante años a soberanos musulmanes como mercenario, no era óbice para su representación como personificación de "fe religiosa, patriotismo, lealtad, honor, galantería" (Merry y Colón y Merry y Villalba, 1889, 68). Con la leyenda de Santiago Matamoros, que presentaba al santo no como un amable peregrino, sino como un brutal "matador de moros", se utilizó un presunto soporte divino para la lucha defensiva nacional. La batalla de Covadonga en torno al año 720 marcó, en este tipo de lectura, el inicio; la caída del último reino musulmán de la península en 1492 representó el final de la mítica época de la reconquista. En esta interpretación, cada batalla, cada conquista de una ciudad gobernada por los musulmanes era una muestra del esfuerzo común de los reyes cristianos. En especial, los historiadores próximos al conservadurismo católico, como Marcelino Menéndez y Pelayo, pasaron por alto las alianzas políticas entre aquellos que profesaban credos distintos, los matrimonios mixtos (en cuanto a la religión de los cónyuges) o el delicado problema de los hijos de tales parejas, que podrían poner en cuestión el postulado de la denominada limpieza de sangre.

La presentación de este pasado como un esfuerzo nacional común contrastaba con un presente surcado por el desgarro social y político. En la política interior, así lo ponían de manifiesto las guerras carlistas entre partidarios del absolutismo y del liberalismo (1833-1839 y 1847-1849), el experimento de la breve Primera República (1873-1874), el restablecimiento de la monarquía borbónica y, en el paso del siglo XIX al XX, los crecientes movimientos autonomistas en las provincias vascas y Cataluña. En la política exterior, España tenía que sufrir igualmente sensibles reveses y aceptar sucesivamente la independencia de las colonias en América y Asia. Además, no se podía pasar por alto el retraso económico respecto de los vecinos de Europa occidental, que superaban a la España agraria. El mito de la reconquista, mediante la adaptación de la unidad y la grandeza histórica, prometía subsanar los dos principales males de España: el desgarro interior y la deteriorada autoconsciencia.

En este sentido los historiadores de diferentes tendencias políticas y religiosas fomentaban la imagen de una reconquista en sus exposiciones de una historia nacional, especialmente en la segunda mitad del siglo XIX (Hertel 2015, 20-33). Menéndez y Pelayo consideraba el catolicismo como elemento fundamental y garante de la unidad de la nación española y la reconquista y el rechazo de las corrientes no católicas como el logro histórico central de España. Para el liberal Modesto Lafuente, autor de la influyente Historia de España, el islam en la Edad Media era, sin más, expresión de "lo no español". Sin embargo, Lafuente no disimulaba una fascinación por lo oriental ni una ambivalente actitud respecto de la expulsión de judíos y musulmanes en los inicios de la Edad moderna por parte de los Reyes Católicos. También un autor como Rafael Altamira, que en el cambio de siglo consideraba el islam más como civilización que como religión, utilizó el concepto de reconquista. Él establecía una distinción entre una función unificadora de la reconquista (ejercida en los heterogéneos reinos cristianos) y otra disociadora (que había provocado al mismo tiempo las diferencias y divergencias entre estos reinos y cuya herencia serían los particularismos del país). De esta manera, Altamira rompía analíticamente el mito de la reconquista, pero sin ponerlo en cuestión radicalmente.

Todo esto tuvo su reflejo en el ámbito educativo, tal y como confirman los manuales de la época. La España islámica se presentaba en todo momento como algo ajeno a la tradición nacional. Podía ser provechosa su aportación al patrimonio de la cultura española, pero hasta la reconquista no se restablecía el nexo con la nacionalidad perdida (la sociedad hispano-goda y católica). Mediante el estudio de los manuales, así, podemos observar que en la escuela de la Restauración predominó, en general, una visión de la historia de España alejada de los planteamientos arabistas y africanistas más "tolerantes"; una visión que, en muchos casos, bebió claramente de la tradición nacional-católica de Menéndez y Pelayo, prácticamente hegemónica en muchos centros privados de 
titularidad religiosa, pero también de la de Modesto Lafuente, igualmente contraria a presentar alAndalus como un momento clave de la historia nacional (Parra, 2007).

La idea de una reconquista con sus implicaciones históricas y actuales fue proclamada no sólo en los libros eruditos o en los manuales escolares españoles. Especialmente en los aniversarios de batallas medievales alcanzó una dimensión pública mucho mayor. Así, a finales del siglo XIX se introdujo un culto a la batalla de Covadonga que fue alabada como la primera victoria contra los musulmanes en el siglo VIII y, de esa manera, como "cuna de la reconquista": un proceso que culminó en la construcción de una nueva basílica y en la fiesta conmemorativa de 1918 (Boyd, 2002; Boyd, 2006). La celebración de la batalla de las Navas de Tolosa (1912) se convirtió en la fiesta de la fundación de Navarra con el correspondiente homenaje al rey Sancho VII (Hertel, 2015, 107-111). En estas fiestas, oradores y predicadores celebraron la idea de la guerra contra el islam como aportación genuina de la nación española y evocaron valores como fe, patriotismo y espíritu de resistencia. El grado con que se remarcaba y acentuaba cada uno de estos componentes dependía de la orientación política y religiosa de cada uno de ellos. En las interpretaciones católicas se presentaba la victoria contra "Africa" y el "Gran Turco" como "mandato prescrito por la misma mano derecha de Dios" (Pidal y Mon, 1912), mientras otras interpretaciones liberales celebraban batallas como la de Covadonga como punto de partida de la "libertad de la patria y la independencia peninsular" (Canella y Secades, 1918, 222).

El mito político de la reconquista tuvo mucho impacto en varios aspectos. En cuanto al contenido tenía la capacidad de estructurar y conferir sentido al pasado y presente de la nación española decimonónica. Con variaciones lo siguieron escribiendo figuras tanto del campo liberal como conservador. Así, no se quedó sólo en debates elitistas o académicos, sino que se trasmitió a un público más amplio mediante los libros escolares, fiestas conmemorativas o fiestas locales (Valls, 2008). También las fiestas de moros y cristianos apelaban al mito de la reconquista. Las fiestas proponían de muchas maneras representar la conquista histórica de una ciudad por los moros y su reconquista final por los cristianos. De esa manera, cada ciudad, cada pueblo podía proyectar una versión local del mito y pasar a formar parte de uno de los episodios más importantes del relato histórico nacional.

\section{EL DESARROLLO DE LAS FIESTAS DE MOROS Y CRISTIANOS EN EL SIGLO XIX}

Las fiestas de moros y cristianos surgieron sobre todo en regiones con una fuerte y dilatada presencia histórica del islam como Andalucía y el antiguo reino de Valencia. El País Valenciano históricamente fue patria de muchos moriscos (descendientes bautizados de los musulmanes) que fueron expulsados de España en 1609. El recuerdo de esta presencia histórica parece haber sido un factor que ha favorecido la aparición de las fiestas de moros y cristianos: también otras regiones del espacio mediterráneo con presencia histórica del islam como Portugal, el sur de Italia, Córcega o Sicilia celebraban o celebran batallas escenificadas contra moros o turcos (Puccio-Den, 2009; d'Agostino, 2003; Alge, 2010; Raposo, 1998). Igualmente existen en regiones de España con menor presencia musulmana histórica como Galicia (Rodríguez Campos, 1997; Taboada Chivite, 1980). Las fiestas se extendieron también a otras partes del mundo: gracias a mecanismos de transferencia cultural luchan hoy moros y cristianos también en América o África (Ponce Herrero, 2017; Barreto, 1996; da Câmara Cascudo, 2001).

Las fiestas del siglo XIX se construyeron sobre una mezcla de tradiciones más antiguas tales como desfiles militares, representaciones teatrales, comedias y procesiones de santos. Exhibiciones de combates entre moros y cristianos eran en las cortes medievales un apreciado entretenimiento. Con ocasión de la boda del conde Ramón Berenguer IV de Barcelona con Petronila de Aragón, en 1150 en Lérida, tuvo lugar una "danza de moros y cristianos con reñido combate", que posiblemente se hizo como celebración simbólica de la victoria que el conde había conseguido un año antes conquistando la ciudad a los musulmanes (Harris, 1994, 46; Brisset Martín, 2001). Por lo 
visto, estas representaciones eran habituales en las ciudades de las costas mediterráneas en los siglos XIII y XIV (Brisset Martín, 1988, 403-407). Una derivada de la tradición posterior tiene sus raíces en las reformas militares de Felipe II: como entrenamiento de los soldados se utilizaban las soldadescas, simulaciones coreografiadas de batallas (Grima Cervantes, 1993). En las fiestas patronales locales los soldados tomaban parte en las procesiones con imágenes de los santos (Harris, 1994, 46).

En la ciudad de Alcoi, como se verá más adelante con más detalle, parece que se estableció la escenificación regular de una batalla entre moros y cristianos entre 1609 y 1688 (Mansanet Ribes, 1991, 24). Las fiestas en los siglos XVII y XVIII se consideraban como un elemento consolidado de la vida de la ciudad lo muestran las interrupciones constatadas en la época de la Guerra de Sucesión española y a causa de una plaga de langosta en 1756 y en 1757 (Mansanet Ribes, 1991, 83). En el siglo XIX las fiestas fueron cambiando con las transformaciones económicas y sociales. Alcoi se desarrolló como un centro de la industria textil y papelera. Esto favoreció por una parte el desarrollo de una burguesía local y, por otra, de una amplia clase de trabajadores. Alcoi fue conocido internacionalmente a causa de la Revolució del Petroli (julio de 1873), en la que trabajadores rebelados mataron al alcalde y controlaron la ciudad durante unos días y a la que Carlos Marx dedicó un artículo político (Marx, 1972 [1873]).

¿Hubo una conexión entre los conflictos relatados y solucionados simbólicamente en el mundo de las fiestas y la sociedad industrial cada vez más dividida, como presumen algunos investigadores (Domene Verdú y Sempere Bernal, 1989, 206 y 209)? Es probable, pero difícilmente constatable. En cualquier caso, los moros y cristianos eras fiestas sobre todo de las clases altas, de los que formaban parte de la burguesía y mostraban su influencia con lujosos vestidos y adornos (Domene Verdú, 2002, 365). La creación de nuevas filaes (agrupaciones festivas) en el siglo XIX permiten conjeturar su creciente popularidad (Mansanet Ribes, 1991, 43).

La identidad local se manifestaba también iconográficamente: Sant Jordi, el patrono local (cuya festividad se celebra el 23 de abril) aparecía no como el que mata al dragón de la leyenda cristiana, sino como el que mata a los moros, al igual que Santiago Matamoros. Sant Jordi lleva en la mano una flecha, con la que arremete contra los moros y los pone a sus pies, como se le encargó por primera vez en 1810 al artista valenciano José Pérez Broquer (Mansanet Ribes, 1991, 43). Con esta proximidad iconográfica a Santiago se adaptó un símbolo nacional a una ciudad: una aportación local al gran mito.

En 1853 un historiador de Barcelona, Josep Antoni Llobet i Vall-Llosera, analizó la fiesta de Alcoi y su historia (Llobet i Vall-Llosera, 1998 [1853]). A él le debemos una de las pocas descripciones exactas de la fiesta en el siglo XIX: la fiesta empezaba el día 22 de abril con la entrada por la ciudad, primero, de las tropas cristianas y, luego, de las moras, dirigidas por un capitán, que cambiaba cada año. El día de Sant Jordi empezaba con la diana, la llamada militar al alba. Ese era el momento en que más claramente se manifestaba el elemento religioso de la fiesta: moros y cristianos acompañaban la procesión de la imagen del santo por toda la ciudad. El tercer día, el día del alardo (desfile de las tropas) estaba dedicado a la confrontación entre moros y cristianos: un embajador del soberano moro aparecía ante el castillo cristiano y exigía a los cristianos su entrega, cosa que por supuesto éstos rechazaban. Y comenzaba la pelea por el castillo; vencían los moros e izaban simbólicamente la media luna. Por la tarde, se repetía la escena al revés, los cristianos conseguían la reconquista y los moros se rendían. Hoy aún se celebra la fiesta siguiendo esta forma.

Llobet i Vall-Llosera describía minuciosamente anacronismos históricos en los vestidos y textos y criticaba "mil escenas ridículas que podrían ahorrarse". Con todo, en esto no sólo veía una diversión inofensiva, sino que, como intelectual de su tiempo, alababa el "principio original y de nacionalidad que en él descuella" (Llobet i Vall-Llosera, 1998 [1853], 8). En esta ambivalencia entre elementos festivos y cómicos residía el encanto para los espectadores. Según Llobet i VallLlosera, éstos no eran sólo los de la población local, sino también "muchos forasteros, que tan 
grandioso espectáculo atrae" (Llobet i Vall-Llosera, 1998 [1853], 3). A partir de elementos religiosos y seculares-carnavalescos surgió un nuevo tipo de fiesta, en que una comunidad se celebraba a sí misma.

Junto a elementos como las batallas y las entradas también había elementos en que se podía comprobar una dirección elitista de las fiestas. Esto se veía especialmente en las embajadas, los diálogos de confrontación entre moros y cristianos que precedían a cada combate por el castillo; son una fuente clave, porque en ellas se puede entrever de una manera más clara las interpretaciones respectivas del mito de la reconquista. En muchas ciudades existían textos precedentes más antiguos que seguían el modelo de las comedias de siglos precedentes y que, de manera creciente a partir de la mitad del siglo XIX, fueron completados o sustituidos por nuevos textos (Domene Verdú y Molina Berenguer, 2003). Los autores de estos textos pertenecían a la élite erudita regional, como por ejemplo el poeta Juan Bautista Pastor Aicart, autor de tres embajadas en diferentes ciudades, o el abogado José Vicente Senabre Vilaplana (Monter Pérez, 2017).

En estas embajadas había elementos repetidos como fórmulas: los insultos recíprocos, la confirmación de la fe en Dios y en Alá y la evocación de Mahoma y de los héroes nacionales cristianos. En los textos los autores recurrían a los topoi del mito de la reconquista y otras batallas históricas adaptándolos a la comunidad local. En la embajada del pueblo de Castalla el capitán cristiano recordaba a su desafiador islámico: "Si es cierto que en Guadalete /se apagó la viva llama/del entusiasmo de Iberia/Castalla, nueva Numancia /avivará sus cenizas [...]. Si [...] godos hubo, que a los árabes/evitaron cien batallas/no seguiremos ejemplo tan detestable" (Infantes y Olivares, 1879, 142).

Los cristianos se llamaban a sí mismos "nietos de Pelayo" o "retoños ... de las mesnadas del Cid" (Pastor y Aycart, 1878, 96). De esta manera se establecía una relación ideal genealógica con los mitos de la reconquista.

Cabe destacar una cierta mezcla de connotaciones regionales dentro de las representaciones de los cristianos: unas veces los soldados cristianos nombran en las embajadas a los héroes más importantes de Aragón, al rey Jaume I, otras al castellano Cid (Pastor Aicart, 2003 [1878], 93; Senabre Villaplana, 2003 [1852], 266; Pastor Aicart 2003 [s. a.], 192 y 194). Llobet i Vall-Llosera observaba en Alcoi que el santo y seña de los cristianos aragoneses no tendría que haber sido "viva España" como en la embajada, sino "viva Aragón”/Llobet i Vall-Llosera, 1998 [1853], 8). Los moros, a su vez, aparecían como personificaciones de los estereotipos orientalistas del siglo XIX y amenazaban a los cristianos con frases-cliché como "De alfombra nos sirva su enseña de guerra; su fuerte castillo nos sirva de harén" (Pastor y Aycart s. a., 192). Que los cristianos los denominaran en muchas embajadas como "africanos" o como "hijos del desierto", subrayaba no sólo un antagonismo religioso, sino también territorial, que conectaba con la idea de una nación espacialmente cerrada.

Un aire elitista de las fiestas se muestra también en la lengua utilizada en las embajadas, escritas siempre en castellano y no en la variante valenciana del catalán propia de la región. Desde el siglo XVI el castellano se usaba mucho pública y oficialmente. En el siglo XVIII, a causa del celo centralista de la Iglesia católica, la lengua catalana fue desapareciendo de los oficios religiosos (Pitarch, 1980; Canet i Llido, 2007). En las comarcas valencianoparlantes de la Comunitat Valenciana del siglo XIX, esta variedad de la lengua catalana era usada en los asuntos no oficiales y en la vida cotidiana por la mayor parte de las clases sociales. El castellano era lengua de lo público y de la cultura, dominaba en los oficios religiosos, en la enseñanza y en la prensa (Montoya Abat, 1997, 41-53; Archiles y Martí Martínez, 1999; Millán, 2004). Sin embargo, no se ponía en cuestión una identidad valenciana: la lengua propia no era inevitablemente una parte constitutiva definitiva de la identidad colectiva (Millán, 2004, 86). En suma, los mecanismos del uso de la lengua en la Comunitat Valenciana de esa época eran complejos y hasta hoy varían de una ciudad a otra. En cualquier caso, las embajadas castellanas subrayan su origen en círculos letrados, que dominaban el castellano escrito. Acentúan una intención didáctica y sobre todo el carácter público de las fiestas. 
Las embajadas eran portadoras del relato histórico central del siglo XIX. En relación con la dimensión performativa de las fiestas no se debería sobrevalorar su efectividad: posiblemente, los últimos versos de las embajadas desaparecían entre el humo y el ruido de las explosiones de pólvora tan abundantes al final. En cualquier caso, las embajadas, como las fiestas en general, representan un canal más de divulgación del mito de la reconquista. A diferencia de los libros de historia y de los manuales escolares (Valls, 2008) llegaba a un amplio público, una parte de la población poco formada o iletrada, que no era el actor central de la fiesta, sino más bien su espectador. Al menos a esta parte de la población las fiestas podían ofrecerle el sentimiento de que una guerra entre moros y cristianos era de algún modo importante para el lugar y su historia: de forma rudimentaria aprendía lo que, de forma elaborada, los pertenecientes a las élites cultas también podían leer en sus libros.

\section{LAS FIESTAS EN EL SIGLO XX}

La confluencia de elementos carnavalescos y los que proceden de tradiciones religiosas prosiguió en el siglo XX. Estos últimos se manifestaron en la laicista Segunda República, que equiparó todas las confesiones religiosas y suprimió privilegios eclesiásticos. En 1931 los miembros del nuevo consejo municipal de Alcoi no participaron en la procesión. Al principio se interpretó la marsellesa como expresión del espíritu republicano (Berenguer Barceló, 1974, 614617); al año siguiente el consejo municipal prohibió completamente los elementos religiosos y la Associació Sant Jordi, que se encargaba de la organización de la fiesta desde 1880, como protesta se retiró de su preparación. En el programa se anunció la fiesta simplemente como "Fiestas y ferias populares, abril 1932" y desapareció la figura de Sant Jordi (Berenguer Barceló, 1974, 639). En noviembre de 1936 Valencia se convirtió en sede provisional del gobierno porque Madrid se encontraba envuelta en los combates de la guerra civil; en Alcoi y en la mayoría de los pueblos, si no en todos, que celebraban esta tradición, no hubo fiestas.

Al menosprecio de las fiestas en la República siguió un renovado interés en los primeros años del franquismo. A Francisco Franco, que había pasado la mayor parte de su carrera militar en Marruecos y en la Guerra civil había contado con el apoyo de tropas mercenarias marroquíes, en los primeros años de su dominio le incomodó una supuesta hermandad entre cristianos y musulmanes. Los ideólogos de Franco interpretaban las fiestas de moros y cristianos no como confrontación entre religiones, sino como prueba de las seculares relaciones amistosas entre España y el Norte de África. Publicaciones como la del Instituto General Franco para la investigación hispano-árabe, una de las instituciones que tenían que dar una pátina científica a los esfuerzos de expansión franquista en Marruecos (Beltrán, 1968, 318; Larramendi y Azaloa Piazza, 2006, 87), subrayaban:

"Las luchas auténticas de moros y cristianos de la Reconquista y de ambos países hasta principios del siglo XIX, tenían un sentido y una significación preeminentemente política; desaparecidas esas circunstancias, no existe nada que se oponga a la convivencia cordial y fecunda de ambos pueblos [...]" (García Figueras, 1939, 4-5; García Figueras, 1940).

Esto no sustituyó sin embargo el mito de la reconquista o la imagen de una nueva "cruzada contra los infieles", que Franco enarboló como propia, si bien los "infieles" eran sobre todo sus enemigos políticos dentro de España. La idea de la reconquista se actualizó con un nuevo contenido franquista. Esto comportó cambios en los textos en muchas fiestas de moros y cristianos. En Laroles de la Alpujarra (Granada) el general del ejército cristiano del siglo XIII, Guzmán el Bueno, se parangonaba con el general José Moscardó, el defensor del Alcázar de Toledo y protagonista de uno de los mitos franquistas más importantes de la Guerra civil (Baumann, 1991, 71). Franco aparecía en la embajada de Benadalid (Málaga) como magnánimo héroe que perdona, que "no gusta ver abatidos a los reyes y monarcas por mas pérfidos que fueran/y de condición tirana/sólo le contenta verlos/obedientes a sus armas" (García Figueras, 1939, 666). El contraste con el 
comportamiento de Franco, hecho ya caudillo, con sus adversarios en la realidad política no podría haber sido mayor.

También todo esto tuvo un reflejo evidente en el ámbito escolar. El régimen franquista hizo uso de discursos de fraternidad hispanoárabe para su política exterior mientras seguía difundiendo los relatos tradicionales de la reconquista para consumo interno. El franquismo, por tanto, manejó varios discursos sobre el pasado islámico de España en función de sus intereses. En el caso de la enseñanza en los centros educativos de la España peninsular, todo apunta a que el régimen no sólo no pretendió incorporar al "otro" por excelencia en su discurso nacional, sino que ni siquiera tuvo intención de popularizar las visiones más "tolerantes" y "respetuosas" que importantes sectores del africanismo español defendieron durante años, reproduciendo un viejo discurso maurofóbico de gran arraigo social que la dictadura nunca pretendió erradicar (Parra, 2016).

En la transición hacia la democracia, cuando España ya era uno de los destinos turísticos más importantes en Europa, se exaltaron y promocionaron fiestas atractivas en el ámbito regional, nacional e internacional. En 1980 la Secretaria de Estado de Turismo concedió a los moros y cristianos de Alcoi el máximo título honorífico de "Fiesta de Interés Turístico Internacional", junto con otras fiestas mundialmente conocidas como la Feria de Abril de Sevilla, la Semana Santa de Málaga o la Procesión del Corpus de Toledo (Boletín Oficial del Estado, 16 de febrero de 1980, 3783-3784). La fiesta de moros y cristianos de la Vilajoiosa, que se representa en el mar con el desembarco de los moros, recibió también este título. Con el resurgimiento de nacionalismos regionales después de la dictadura, héroes cristianos regionales de la época medieval fueron introducidos en las fiestas; filaes moras recibieron nombres de importantes califatos, guerreros y sultanes o nombres en árabe (Guia, 2014, 149). Las mujeres, en muchas fiestas marginalizadas hasta los años 80, empezaron a cuestionar normas que les redujeron a un mero "adorno" en las fiestas o incluso prohibieron su participación (Guia, 2014, 150-151). Por último, la inmigración de musulmanes a partir de los años 1980 llevó a la reflexión crítica de las fiestas mencionada arriba, un proceso que continúa en nuestros días. A pesar de -o justamente por- todas estas discusiones, la popularidad de las fiestas continúa e incluso sigue en ascenso.

Este tipo de festividades ha tenido también su impacto en el ámbito educativo a través de celebraciones escolares que, de manera ritualizada, se celebran año tras año en los colegios. Estas conmemoraciones, fronterizas entre el mundo escolar y el contexto sociocultural más amplio, incorporan elementos del sentido común socialmente aceptado, es decir, aspectos de un complejo de creencias, presupuestos, costumbres, imágenes y prácticas que tienen una existencia mundana y banal (no reflexiva) en el día a día. En este sentido, contribuyen a reproducir, de un modo acrítico, los mismos estereotipos y prejuicios que encontramos en las celebraciones locales sobre el nosotros y el ellos, lo que dificulta el desarrollo de un espacio escolar crítico que fomente la interculturalidad y la construcción de identidades abiertas y plurales (Parra y Segarra, 2012).

\section{CONCLuSIÓn}

Viendo el desarrollo histórico de las fiestas desde el siglo XIX hasta hoy, se puede decir que éstas tenían a menudo la función de celebrar y fortalecer un nosotros. La imagen de este nosotros y, por tanto, también del otro ha ido cambiando históricamente y estaba y aún está hoy abierto a diferentes interpretaciones. Este cambio y sus causas pueden resumirse así:

Tras el final de la presencia musulmana real surgieron en el territorio de la actual Comunitat Valenciana tradiciones festivas que tenían lugar con ocasión de las diferentes fiestas patronales. En estas tradiciones confluían elementos religiosos y seculares como el culto a los santos, procesiones y coreografías de batallas. En Alcoi, en el curso de los siglos XVII y XVIII, estas fiestas se convirtieron en una parte constitutiva de la vida de la ciudad. Las élites burguesas del siglo XIX tomaron elementos de esta tradición, porque podían utilizarlas para su autorepresentación. De la transformación de las fiestas en ese tiempo dan cuenta el aumento de nuevas agrupaciones de 
fiestas, pero también cambios de contenido, visibles en la imagen histórica transmitida. El mito político de la reconquista como relato histórico principal del siglo XIX se introdujo en las fiestas de moros y cristianos sobre todo en las embajadas. La victoria contra los moros, recordada ya desde siglos, se explicitaba ahora como acción heroica de la nación que era el modelo del nuevo orden político. De esta manera, con la victoria local contra los moros, cada pueblo podía insertarse en un empeño mayor, el de una nación española y así revalorizar y convertir en héroe a la propia comunidad.

En la Segunda República se vio cómo el intento de construcción de un Estado secular comportaba eliminar los elementos eclesiásticos-religiosos o los que eran percibidos como tales. A causa de la poca duración de la Segunda República no se consiguió institucionalizar nuevos rituales seculares. También los ideólogos franquistas trataron de introducir sus imágenes históricas en las fiestas. Franco y otros héroes franquistas aparecían en los textos, mientras las fiestas como tales no fueron interpretadas como prueba de una hostilidad entre el islam y el cristianismo, sino como parte de una larga relación y expresión de una nueva amistad.

La España democrática tras la dictadura se interesó por las fiestas para utilizarlas a favor del factor económico del turismo, que iba ganado cada vez más importancia. Por eso, se introdujo una armonización folclorística de la contraposición de moros y cristianos, visible por ejemplo en el paralelismo del simbolismo cristiano y moro en los carteles de las fiestas (Flesler y Pérez Melgosa, 2003, 161-163). Como se ha visto arriba, los cambios en la sociedad española y mundial han despertado y despiertan aún discusiones sobre el carácter y la manera de celebrar las fiestas, especialmente respecto a la participación y el papel de mujeres y respecto a la presencia de inmigrantes musulmanes; pero ello no ha evitado que hayan penetrado en ámbitos tan importantes como el escolar, donde se celebran, año tras año, de manera ritualizada.

Los mecanismos de construir identidad y alteridad son más complejos que una simple dicotomía entre un nosotros y un otro asociado con algo o alguien diferente en sentido religioso, cultural, étnico, social o territorial (Monter Pérez, 2017), lo que se ve especialmente en comparación con parecidas fiestas en Portugal (Hertel, 2015, 138-140). Las fiestas de moros y cristianos también responden -histórica y actualmente- a la necesidad universal de la situación festiva de excepción. A la situación de un tiempo festivo opuesto a lo cotidiano le viene a propósito que el moro, como mítico antagonista de España, encarne, sin más, también el "otro tiempo" de la fiesta (Harris, 1994, 47). Aunque las fiestas giran en torno a un antagonismo interpretado a lo largo de los siglos de manera diferente, sea entre "lo cristiano" y "lo moro", "lo religioso" y "lo secular", "lo familiar" y "lo exótico", "lo cotidiano" y "lo festivo", las líneas de identidad y alteridad no son siempre tan claras, especialmente en nuestros días. Más allá de esto, el ritual festivo en sí creaba propuestas de identidad (y alteridad) para los que participaron: como miembros de grupos sociales, de determinadas filaes, como ciudadanos de una ciudad o de toda una región para cual la existencia de fiestas moros y cristianos sirve como seña de identidad. Moros y cristianos juntos podían y pueden negociar identificaciones múltiples y a veces de manera más sutil de lo que pueda parecer a primera vista. Al fin y al cabo, también en este sentido, son juegos de identidad .

\section{Referencias}

Agostino, G. d'. (2003). Moros y cristianos en la cultura tradicional siciliana. En M. Albert-Llorca, M. y J. A. González Alcantud (eds.), Moros y cristianos: representaciones del otro en las fiestas del Mediterráneo occidental (pp. 163-176). Toulouse: Presses universitaires du Mirail.

Albert-Llorca, M. y González Alcantud, J. A. (eds.) (2003). Moros y cristianos: representaciones del otro en las fiestas del Mediterráneo occidental. Toulouse: Presses universitaires du Mirail. 
Alge, B. (2010). Die Performance des Mouro in Nordportugal. Eine Studie von Tanzdramen in religiösen Kontexten. Berlin: Verlag für Wissen und Bildung.

Archilés, F. y Martí, M. (1999). La construcción de la Nación española durante el siglo XIX: logros y límites de la asimilación en el caso valenciano. Ayer, 35 (1999), 171-190.

Barreto, L. A. (1996). Cristãos e mouros na cultura brasileira. En B. do Nascimento (ed.), EuroAmérica: Uma realidade comum? (pp. 153-172). Rio de Janeiro: Comissão Nacional de Folclore.

Baumann, R. E. (1991). Moors, Demons and Arabs: The Changing Significance of "Moros y Christianos" Performances in the Alpujarra, Spain. Human Mosaic, 25, 66-73.

Beltrán, L. (1968). African Studies in Spain. African Studies Bulletin, 3, 316-325.

Berenguer Barceló, J. (1974). Historia de los Moros y Cristianos de Alcoy. Alcoy: Imp. Belguer.

Boyd, C. P. (2002). The Second Battle of Covadonga: The Politics of Commemoration in Modern Spain. History and Memory, 2, 37-64.

Boyd, C. P. (2006). Covadonga y el regionalismo asturiano. Ayer, 64, 149-178.

Brisset Martín, D. E. (1988). Representaciones rituales hispánicas de conquista. Madrid: Editorial de la Universidad Complutense.

Brisset Martín, D. E. (2001). Fiestas hispanas de moros y cristianos. Historia y significados. Gazeta de Antropología, 17. Recuperado de http://www.ugr.es/ pwlac/G17_03DemetrioE_Brisset _Martin.html [2 de julio de 2018].

Bronisch, A. P. (1998). Reconquista und Heiliger Krieg. Die Deutung des Krieges im christlichen Spanien von den Westgoten bis ins frühe 12. Jahrhundert. Münster: Aschendorff.

Canella y Secades, F. (1918). De Covadonga. Contribución al XII centenario. Madrid: Establecimiento Tipográfico de Jaime Rates.

Canet i Llidó, V. (2007). El valencià en l'església: 1707-2007. Anuari de l'Agrupació Borrianenca de Cultura: revista de recerca humanística i científica, 18, 93-110.

Cascudo, L. da Câmara (2001). Mouros, Franceses e Judeus. Três Presenças no Brasil. São Paulo: Editora Perspectiva.

Domene Verdú, J. F. (2002). Síntesis histórica de las Fiestas de Moros y Cristianos. En III Congreso Nacional de fiestas de moros y cristianos (pp. 353-376). Murcia: Unión Nacional de Entidades Festeras de Moros y Cristianos (UNDEF).

Domene Verdú, J. F. (2015). Las fiestas de moros y cristianos. Sant Vicent del Raspeig: Publicacions de la Universitat d'Alacant.

Domene Verdú, J. F. y Molina Berenguer, M. (2003). Textos de las embajadas de la fiesta de moros y cristianos. Alacant: Unión Nacional de Entidades Festeras de Moros y Cristianos (UNDEF).

Domene Verdú, J. F. y Sempere Bernal, A. (1989). Las fiestas de Moros y Cristianos de Villena. Alicante: Instituto de Estudios Juan Gil-Albert.

Flesler, D. y Pérez Melgosa, A. (2003). Battles of Identity, or Playing "Guest" and "Host": the Festivals of Moors and Christians in the Context of Moroccan Immigration in Spain. Journal of Spanish Cultural Studies, 4, 2, 151-168.

García Figueras, T. (1939). Notas sobre las fiestas de moros y cristianos en Benadalid (Málaga). Larache: Artes Gráficas Boscá.

García Figueras, T. (1940). Notas sobre las fiestas de "moros y cristianos" en España. Vol. II: Las fiestas de San Jorge, en Alcoy. Tetuán: Instituto General Franco para la investigación hispano-árabe.

Grima Cervantes, J. A. (1993). Estudio preliminar. En R. de Cala y López y M. F. González-Grano de Oro, La fiesta de Moros y Cristianos en la Villa de Carboneras precedida de una noticia histórica. Almería: Instituto de Estudios Almerienses.

Guia, A. (2014). The Muslim Struggle for Civil Rights in Spain: Promoting Democracy Through Migrant Engagement, 1985-2010. Brighton: Sussex Academic Press. 
Harris, M. (1994). Muhammed and the Virgin: Folk Dramatizations of Battles Between Moors and Christians in Modern Spain. The Drama Review, 1, 45-61.

Hertel, P. (2015). The Crescent Remembered: Islam and Nationalism on the Iberian Peninsula. Brighton: Sussex Academic Press.

Hobsbawm, E. (2006 [1983]). Introduction: Inventing Traditions. En E. Hobsbawm y T. Ranger (eds.), The Invention of Tradition (pp. 1-14). Cambridge: Cambridge University Press.

Infantes y Olivares, E. (2003 [1879]). Embajada de Castalla (1879). J. F. Domene Verdú y M. Molina Berenguer, Textos de las embajadas de la fiesta de moros y cristianos (pp. 141-145). Alacant: UNDEF.

Kottmann, S. L. (2009). Moros en la Costa! - Mauren an christlichen Ufern. Abwehr und Inkorporation des Fremden im Süden Spaniens. Peripherie, 114/115, 282-303.

Krom, M. J. C. (2008). Festivals of Moors and Christians: Performance, Commodity and Identity in Folk Celebrations in Southern Spain. Journal of Mediterranean Studies, 1, 119-138.

Larramendi, M. H. de y Azaloa Piazza, B. (2006). Los estudios sobre el Mundo Árabe y Mediterráneo Contemporáneos en España. En I. Martín y R. Gillespie (eds.), Investigando el Mediterráneo (pp. 87-148). Barcelona: British Council.

Llobet i Vall-Llosera, J. A. (1998 [1853]). Apuntes históricos acerca de las fiestas que celebra cada año la ciudad de Alcoy a su Patrón San Jorge con referencias a la historia antigua de la misma ciudad en los tiempos de la reconquista sobre los árabes. Alcoi: Misèria y Companyia.

Mansanet Ribes, J. L. (1991). La Fiesta de Moros y Cristianos de Alcoy y su Historia. Alcoy: Artes Gráficas.

Marx, K. (1972 [1873]). Die Bakunisten an der Arbeit. Denkschrift über den Aufstand in Spanien im Sommer 1873. En K. Marx y F. Engels, Werke, vol. 18 (pp. 476-493). Berlin (RDA): Dietz.

Merry y Colón, M. y Merry y Villalba, A. (1889). Compendio de la historia de España. Sevilla: Imprensa y Litografia de José Ma Ariza.

Millán, J. (2004). El País Valencià en l'inici de l'Estat centralista del vuit-cents. Una aproximació. En L'Estat-nació i el conflicte regional. Joan Mañé i Flaquer, un cas paradigmàtic (pp. 6390). Barcelona: Publicacions de l'Abadia de Montserrat.

Monter Pérez, J. (2018). Nosaltres, en busca de la identitat. Reflexió a partir de les Ambaixades de J. V. Senabre Vilaplana. Revista oficial de festes Moros $i$ Cristians, 54-56.

Montoya Abat, B. (1996). Alacant, la llengua interrompuda. València: Comercial Denes.

Parra Monserrat, D. (2007). Islam e identidad en la escuela franquista. Imágenes y tópicos a través de los manuales. Didáctica de las Ciencias Experimentales y Sociales, 21,15-32.

Parra Monserrat, D. (2016). Africanismo e arabismo no relato histórico escolar: Espanha, 19391956. História. Revista da FLUP. IV Série, vol. 6, 89-101.

Parra Monserrat, D. y Segarra Estarelles, J. R. (2012). Celebraciones escolares, ¿fiestas cívicas? El tratamiento escolar del 9 de octubre y del día de la Constitución en las aulas valencianas de Primaria. Didáctica de las Ciencias Experimentales y Sociales, 26, 19-34. DOI: 10.7203/DCES.26.1927.

Pastor Aicart, J. B. (2003 [1878]). Embajada de Beneixama. En J. F. Domene Verdú y M. Molina Berenguer, Textos de las embajadas de la fiesta de moros y cristianos (pp. 93-102). Alacant: UNDEF.

Pastor Aicart, J. B. (2003 [s. a.]). Embajada de Fontanars dels Alforins. En J. F. Domene Verdú y M. Molina Berenguer, Textos de las embajadas de la fiesta de moros y cristianos (pp. 191194). Alacant: Unión Nacional de Entidades Festeras de Moros y Cristianos UNDEF.

Pidal y Mon, A. (1912). Discurso sobre la batalla de Las Navas de Tolosa. Madrid: Tipografía de la Revista de Archivos, Bibliotecas y Museos. 
Pitarch, V. (1980). La llengua de l'administració eclesiàstica (País Valencià, segles XVII-XVIII). L'Espill, 6/7, 41-76.

Ponce Herrero, G. (ed.) (2017). Moros y cristianos, un patrimonio mundial. Alicante: Universidad de Alicante y Unión Nacional de Entidades Festeras de Moros y Cristianos (UNDEF).

Puccio-Den, D. (2009). Les Théâtres de "Maures et Chrétiens". Conflits politiques et dispositifs de réconciliation (Espagne, Sicile, XVIIe-XXIe siècles).Turnhout: Brepols.

Raposo, P. (1998). O Auto da Floripes: Cultura popular, etnógrafos, intelectuais e artistas. Etnografia, 2, 189-219.

Ríos Saloma, M. F. (2005). De la Restauración a la Reconquista: la construcción de un mito nacional. Una revisión historiográfica. Siglos XVI-XIX. En la España Medieval, 28, 379414.

Ríos Saloma, M. F. (2006). La Reconquista: una invención historiográfica (siglos XVI-XIX). En D. Baloup y P. Josserand (eds.), Regards croisés sur la Guerre Sainte. Guerre, idéologie et religion dans l'espace méditerranéen latin (XIe-XIIIe siècle) (pp. 413-429). Toulouse: Presse universitaire du Mirail.

Rodríguez Campos, X. (1997). As festas patronais e a identidade en Galícia. En Galicia. Antropoloxía, vol. XXVII: Relixión. Crenzas. Festas (pp. 354-375). A Coruña: Hércules de Ediciones.

Senabre Vilaplana, J. V. (2003 [1852]). Embajada de Muro de l'Alcoi (1852). En J. F. Domene Verdú y M. Molina Berenguer, Textos de las embajadas de la fiesta de moros y cristianos (pp. 263-268). Alacant: UNDEF.

Taboada Chivite, X. (1980). Moros y cristianos en tierras de Laza (Orense). En id., Ritos y creencias gallegas (pp. 59-77). A Coruña: Sálvora.

Valls, R. (2008). La imagen del islam en los actuales manuales escolares españoles de historia. En L. Cajani (dir.), Conociendo al otro. El islam y Europa en sus manuales de historia (pp. 73122). Madrid: Santillana.

\section{Cómo CITAR ESTE ARTí́CULO}

Hertel, P. (2018). Juegos de identidad. Las fiestas de moros y cristianos como difusoras de una narrativa histórica nacional. Didáctica de las ciencias experimentales y sociales, 35, 45-58. DOI: 10.7203/DCES.35.13679. 